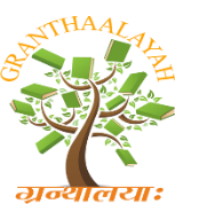

\author{
INTERNATIONAL JOURNAL OF RESEARCH \\ GRANTHAALAYAH \\ A knowledge Repository
}

Science

\title{
HYBRIDIZATION OF ANT COLONY ALGORITHM AND PARTICLE SWARM OPTIMIZATION ALGORITHM FOR REDUCTION OF REAL POWER LOSS
}

\author{
Dr K. Lenin *1 \\ ${ }^{* 1}$ Professor, Department of EEE, Prasad V.Potluri Siddhartha Institute of Technology, Kanuru, \\ Vijayawada, Andhra Pradesh -520007, India
}

\begin{abstract}
In this work Ant colony optimization algorithm (ACO) \& particle swarm optimization (PSO) algorithm has been hybridized (called as APA) to solve the optimal reactive power problem. In this algorithm, initial optimization is achieved by particle swarm optimization algorithm and then the optimization process is carry out by ACO around the best solution found by PSO to finely explore the design space. In order to evaluate the proposed APA, it has been tested on IEEE 300 bus system and compared to other standard algorithms. Simulations results show that proposed APA algorithm performs well in reducing the real power loss.
\end{abstract}

Keywords: Swarm Intelligence; Optimal Reactive Power; Transmission Loss.

Cite This Article: Dr K. Lenin. (2018). "HYBRIDIZATION OF ANT COLONY ALGORITHM AND PARTICLE SWARM OPTIMIZATION ALGORITHM FOR REDUCTION OF REAL POWER LOSS." International Journal of Research - Granthaalayah, 6(12), 121-127. https://doi.org/10.29121/granthaalayah.v6.i12.2018.1092.

\section{Introduction}

Reactive power problem has been the key in power system operation \& control, since it plays major role in secure \& economic operation of the power system. Many conventional techniques [1-6] used for solving the problem. But many drawbacks have been found in the conventional methods and mainly difficulty in handling the inequality constraints. Last two decades many evolutionary algorithms [7-18] continuously applied to solve the problem. In this work PSO, ACO and their combinations are focused [19-31]. PSO was inspired by the social behaviour of organisms such as bird and fish flocking. As compared to other robust design optimization methods PSO is more efficient, requiring fewer number of function evaluations, while leading to better or the same quality of results. Also PSO has some defect such as trapping into local optimum in a complex search space and disability to do a good local search around a local optimum. It is known that the PSO may perform better than the other meta-heuristic optimization techniques in the early iterations, but it does not appear competitive when the number of iterations increases. ACO was inspired by the behaviour of real ant colonies in finding the shortest paths between food sources 
and their nest. ACO was combined with PSO to improve the operation of PSO in for solving the continuous unconstrained problems. In this algorithm, a preliminary optimization is achieved by PSO. Then another optimization process is performed by ACO around the best solution found by PSO to finely explore the design space. In this work, the exterior penalty function method (EPFM) is employed in the framework of the sequential unconstrained minimization technique (SUMT) to handle the constraints. In order to evaluate the proposed APA, it has been tested on IEEE 300 bus system and compared to other standard algorithms. Simulations results show that proposed APA algorithm performs well in reducing the real power loss.

\section{Problem Formulation}

Main aim is to minimize the system real power loss \& given as,

$\mathrm{P}_{\text {loss }}=\sum_{\mathrm{k}=(\mathrm{i}, \mathrm{j})}^{\mathrm{n}=1} \mathrm{~g}_{\mathrm{k}\left(\mathrm{V}_{\mathrm{i}}^{2}+\mathrm{V}_{\mathrm{j}}^{2}-2 \mathrm{~V}_{\mathrm{i}} \mathrm{V}_{\mathrm{j}} \cos \theta_{\mathrm{ij}}\right)}$

Voltage deviation magnitudes (VD) is,

$\operatorname{Min}(\mathrm{VD})=\sum_{\mathrm{k}=1}^{\mathrm{nl}}\left|\mathrm{V}_{\mathrm{k}}-1.00\right|$

Load flow equality constraints:

$P_{G i}-P_{D i}-V_{i} \sum_{j=1}^{n b} V_{j}\left[\begin{array}{cc}G_{i j} & \cos \theta_{i j} \\ +B_{i j} & \sin \theta_{i j}\end{array}\right]=0, i=1,2 \ldots, n b$

$Q_{G i}-Q_{D i}-V_{i \sum_{j=1}^{n b} V_{j}}\left[\begin{array}{cc}G_{i j} & \sin \theta_{i j} \\ +B_{i j} & \cos \theta_{i j}\end{array}\right]=0, i=1,2 \ldots, n b$

Inequality constraints are:

$\mathrm{V}_{\mathrm{Gi}}^{\min } \leq \mathrm{V}_{\mathrm{Gi}} \leq \mathrm{V}_{\mathrm{Gi}}^{\mathrm{max}}, \mathrm{i} \in \mathrm{ng}$

$\mathrm{V}_{\mathrm{Li}}^{\min } \leq \mathrm{V}_{\mathrm{Li}} \leq \mathrm{V}_{\mathrm{Li}}^{\mathrm{max}}, \mathrm{i} \in \mathrm{nl}$

$\mathrm{Q}_{\mathrm{Ci}}^{\min } \leq \mathrm{Q}_{\mathrm{Ci}} \leq \mathrm{Q}_{\mathrm{Ci}}^{\max }, \mathrm{i} \in \mathrm{nc}$

$\mathrm{Q}_{\mathrm{Gi}}^{\min } \leq \mathrm{Q}_{\mathrm{Gi}} \leq \mathrm{Q}_{\mathrm{Gi}}^{\max }, \mathrm{i} \in \mathrm{ng}$

$\mathrm{T}_{\mathrm{i}}^{\min } \leq \mathrm{T}_{\mathrm{i}} \leq \mathrm{T}_{\mathrm{i}}^{\max }, \mathrm{i} \in \mathrm{nt}$

$\mathrm{S}_{\mathrm{Li}}^{\min } \leq \mathrm{S}_{\mathrm{Li}}^{\max }, \mathrm{i} \in \mathrm{nl}$ 


\section{Hybridization of Ant Colony Optimization Algorithm \& Particle Swarm Optimization Algorithm}

\section{Ant Colony Optimization (ACO)}

ACO is based on the cooperative behavior of real ant colonies, which are able to find the shortest path from their nest to a food source. The ACO process can be explained as follows. The ants start at the home node, travel through the various nodes from the first node to the last node, and end at the destination node in each iteration. Each ant can select only one node in each layer in accordance with the state transition rule [27,28]. An ant $k$, when located at node $i$, uses the pheromone trail $\tau_{i j}$ to compute the probability of choosing $j$ as the next node:

$P_{i j}^{(k)}=\left\{\begin{array}{c}\frac{\tau_{i j}^{\alpha}}{\sum_{j \in N_{i}^{k}} \tau_{i j}^{\alpha}} \text { if } j \in N_{i}^{(k)} \\ 0 \text { if } j \notin N_{i}^{(k)}\end{array}\right.$

Where $\alpha$ denotes the degree of importance of the pheromones and $N_{i}^{(k)}$ indicates the set of neighborhood nodes of ant $k$ when located at node $i$. The neighbourhood of node $i$ contain all the nodes directly connected to node $i$ except the predecessor node. This will prevent the ant from returning to the same node visited immediately before node $i$. An ant travels from node to node until it reaches the destination node. Before returning to the home node, the $k$ th ant deposits an amount of pheromone on arcs it has visited. After all the ants return to the nest, the pheromone information is updated in order to increase the pheromone value associated with good or promising paths. The updating is achieved as follows:

$\tau_{i j}=(1-\rho) \tau_{i j}+\Delta \tau_{i j}^{(k)}$

$\Delta \tau_{i j}^{(k)}=\frac{Q}{L_{k}}$

Where $\rho \in(0,1)$ is the pheromone decay factor; $\Delta \tau_{i j}^{(k)}$ is the amount of pheromone deposited on arc $i j$ by the best ant $k$. also, $Q$ is a constant and $L_{k}$ is the length of the path travelled by the $k$ th ant. When more paths are available from the nest to a food source, a colony of ants will be able to exploit the pheromone trails left by the individual ants to discover the shortest path from the nest to the food source and back [28]. In fact, ACO simulates the optimization of ant foraging behaviour.

\section{Particle Swarm Optimization (PSO)}

The PSO has been proposed by Eberhart and Kennedy [29] to simulate the motion of bird swarms. The particle swarm process is stochastic in nature; it uses a velocity vector to update the current position of each particle in the swarm. The velocity vector is updated based on the memory gained by each particle, conceptually resembling an autobiographical memory, as well as the knowledge gained by the swarm as a whole. Thus, the position of each particle in the swarm is updated based on the social behaviour of the swarm which adapts to its environment by returning to promising regions of the space previously discovered and searching for better positions over time. Numerically, the position of the ith particle, $\mathrm{Xi}$, at iteration $\mathrm{t}+1$ is updated as follows: 
$\mathrm{X}_{\mathrm{i}}^{\mathrm{t}+1}=\mathrm{X}_{\mathrm{i}}^{\mathrm{t}}+\mathrm{V}_{\mathrm{i}}^{\mathrm{t}+1}$

Where $\mathrm{V}_{\mathrm{i}}^{\mathrm{t}+1}$ is the corresponding updated velocity vector given as follows:

$V_{i}^{t+1}=\omega V_{i}^{t}+c_{1} r_{1}\left(P_{i}^{t}-X_{i}^{t}\right)+c_{2} r_{2}\left(G_{\text {best }}^{t}-X_{i}^{t}\right)$

Where $V_{i}^{t}$ is the velocity vector at iteration $t, r 1$ and $r 2$ represents random numbers between 0 and 1 ; $\mathrm{P}_{\mathrm{i}}^{\mathrm{t}}$ represents the best ever particle position of particle $\mathrm{i}$, and $\mathrm{G}_{\text {best }}^{\mathrm{t}}$ corresponds to the global best position in the swarm up to iteration $\mathrm{t}$. The remaining terms are problem dependent parameters; in this paper, cognitive parameter, $\mathrm{c} 1$, and c2, social parameter, are considered to be equal to 2. Also, $\omega$ is the inertia weight which plays an important role in the PSO convergence behaviour.

Due to the importance of $\omega$ in achieving efficient search behaviour the optimal updating criterion is taken as follows:

$\omega=\omega_{\max }-\frac{\omega_{\max }-\omega_{\min }}{k_{\max }} \cdot k$

Where $\omega_{\max }$ and $\omega_{\min }$ are the maximum and minimum values of $\omega$, respectively. Also, $k_{\max }$, and $k$ are the number of maximum iterations and the number of present iteration, respectively.

One of the defect known in PSO is that for swarm which have information about the global best solution $\left(G_{\text {best }}\right)$, the second and third part of the velocity update equation (Eq. (15)) is zero, thus swarm's behaviour is on the last motion vector, also because $\omega$ is less than one, this part has been damped and the other swarm converge to the best swarm $\left(G_{\text {best }}\right)$. This is the reason that cause to precocious convergence of algorithm and PSO disable to do a good local search. In order to solve this problem and improve the performance of PSO, new terms has been added to the velocity updating equation.

In this study, in order to improve the computational performance of PSO and ACO are serially integrated at first by using the EPFM and choosing the minor penalty parameter a swarm including $n_{p}$ particles is randomly selected and PSO is employed to achieve a preliminary optimization task. As the $r_{p}$ is small, PSO converges to an infeasible solution. In this process the best solution is saved as $G_{\text {best }}$ in the memory of the algorithm. In the next step, a new swarm is generated based on elitism. The new elite swarm is created by the means of giving more chance to survive the elite particles. In this case, $G_{\text {best }}$ is transformed to the new swarm and the remaining ones are randomly selected as follows:

$X_{j}=N\left(G_{\text {best }}, \alpha G_{\text {best }}\right), j=1,2, \ldots,\left(n_{p}-1\right)$

Where $N\left(G_{\text {best }}, \alpha G_{\text {best }}\right)$ represents a random number normally distributed vector with the mean of $G_{\text {best }}$ and the standard deviation of $\alpha G_{\text {best. }}$. The produced elite swarm is employed by PSO to achieve another optimization process. In this process according to the SUMT concepts, the penalty parameter is increased as:

$r_{p}^{k+1}=10 r_{p}^{k}$ 
This procedure is continued until PSO finds a feasible Gbest. This process is entitled as global search phase (GSP). In the second stage a finer search is implemented about the feasible $G_{\text {best }}$ found by PSO in GSP. A new elite population is created using Eq. (17) and ACO is employed to achieve the optimization task. The best solution found by ACO is considered as the final solution. This later process is termed as local search phase (LSP).

1) Start

2) Initialize $r_{p}$ by a small value

3) Initialize a swarm of $n_{p}$ particles

4) Update particle velocities

5) Update particle positions

6) Score new particles

7) Update $P_{i}^{t}$ and $G_{\text {best }}$

8) Convergence? if yes go next step, else go to step 3

9) Producing new elite swarm:

- $G_{\text {best }}$ from previous optimization process

- $\left(n_{p}-1\right)$ normally distributed random particles

$\left(\mathrm{X}_{j}=N\left(G_{\text {bes }} \mathrm{t}, \alpha G_{\text {best }}\right)\right)$

10) Update $r_{p}$ for a new optimization process

$11)$ Is $G_{\text {best }}$ feasible? If yes go to next step else go to step 3

12) Producing new elite ants:

- $\quad a . G_{\text {best }}$ from GSP

- $b .\left(n_{p}-1\right)$ ants from $\left(\mathrm{X}_{j}=N\left(G_{\text {best }}, \alpha G_{\text {best }}\right)\right)$

13) Construct solution using the pheromone trail and randomization

14) Update the amount of pheromone (Increase for better values and reduce for all others)

15) Convergence? If yes go to step 3, else go to step 13

16) Final solution contains maximum pheromones

\section{Simulation Results}

Finally, IEEE 300 bus syste[34] is used as test system to validate the performance of the proposed Apidae algorithm. Table 3 shows the comparison of real power loss obtained after optimization.

Table 3: comparison of real power loss

\begin{tabular}{|l|l|l|l|l|}
\hline Parameter & Method EGA [33] & Method EEA [33] & Method CSA [32] & APA \\
\hline PLOSS (MW) & 646.2998 & 650.6027 & 635.8942 & 624.0022 \\
\hline
\end{tabular}

\section{Conclusion}

In this work hybridized algorithm, successfully solved the optimal reactive power problem. Initial optimization is achieved by particle swarm optimization algorithm and then the optimization process is carry out by ACO around the best solution found by PSO to finely explore the design space. Proposed APA has been tested in IEEE 300 bus system and compared to other standard algorithms. Simulations results show that proposed APA algorithm performs well in reducing the real power loss. 


\section{References}

[1] K. Y. Lee, "Fuel-cost minimisation for both real and reactive-power dispatches," Proceedings Generation, Transmission and Distribution Conference, vol/issue: 131(3), pp. 85-93, 1984.

[2] N. I. Deeb, "An efficient technique for reactive power dispatch using a revised linear programming approach,” Electric Power System Research, vol/issue: 15(2), pp. 121-134, 1988.

[3] M. R. Bjelogrlic, M. S. Calovic, B. S. Babic, et. al.," Application of Newton's optimal power flow in voltage/reactive power control", IEEE Trans Power System, vol. 5, no. 4, pp. 1447-1454, 1990.

[4] S. Granville, "Optimal reactive dispatch through interior point methods," IEEE Transactions on Power System, vol/issue: 9(1), pp. 136-146, 1994.

[5] N. Grudinin, "Reactive power optimization using successive quadratic programming method," IEEE Transactions on Power System, vol/issue: 13(4), pp. 1219-1225, 1998.

[6] Wei Yan, J. Yu, D. C. Yu and K. Bhattarai," A new optimal reactive power flow model in rectangular form and its solution by predictor corrector primal dual interior point method", IEEE Trans. Pwr. Syst., vol.21, no.1, pp.61-67, 2006.

[7] Aparajita Mukherjee, Vivekananda Mukherjee, "Solution of optimal reactive power dispatch by chaotic krill herd algorithm", IET Gener. Transm. Distrib, Vol. 9, Issue. 15, pp. 2351-2362, 2015.

[8] Hu, Z., Wang, X. \& Taylor, G. Stochastic optimal reactive power dispatch: Formulation and solution method. Electr. Power Energy Syst., vol. 32, pp. 615-621. 2010.

[9] Mahaletchumi A/P Morgan, Nor Rul Hasma Abdullah, Mohd Herwan Sulaiman, Mahfuzah Mustafa and Rosdiyana Samad, "Computational intelligence technique for static VAR compensator (SVC) installation considering multi-contingencies (N-m)", ARPN Journal of Engineering and Applied Sciences, VOL. 10, NO. 22, DECEMBER 2015.

[10] Mohd Herwan Sulaiman, Zuriani Mustaffa, Hamdan Daniyal, Mohd Rusllim Mohamed and Omar Aliman, "Solving Optimal Reactive Power Planning Problem Utilizing Nature Inspired Computing Techniques", ARPN Journal of Engineering and Applied Sciences, VOL. 10, NO. 21, pp.97799785. NOVEMBER 2015

[11] Mohd Herwan Sulaiman, Wong Lo Ing, Zuriani Mustaffa and Mohd Rusllim Mohamed, "Grey Wolf Optimizer for Solving Economic Dispatch Problem with Valve-Loading Effects", ARPN Journal of Engineering and Applied Sciences, VOL. 10, NO. 21, pp. 9796-9801, NOVEMBER 2015.

[12] Pandiarajan, K. \& Babulal, C. K., "Fuzzy harmony search algorithm based optimal power flow for power system security enhancement". International Journal Electric Power Energy Syst., vol. 78, pp. 72-79. 2016.

[13] Mustaffa, Z., Sulaiman, M.H., Yusof, Y., Kamarulzaman, S.F., "A novel hybrid metaheuristic algorithm for short term load forecasting", International Journal of Simulation: Systems, Science and Technology, Volume 17, Issue 41, Pages 6.1-6.6. 2017.

[14] Sulaiman, M.H., Mustaffa, Z., Mohamed, M.R., Aliman, O., "An application of multi-verse optimizer for optimal reactive power dispatch problems", International Journal of Simulation: Systems, Science and Technology, Volume 17, Issue 41, Pages 5.1-5.5. 2017.

[15] Mahaletchumi A/P Morgan, Nor Rul Hasma Abdullah, Mohd Herwan Sulaiman,Mahfuzah Mustafa and Rosdiyana Samad, "Multi-Objective Evolutionary Programming (MOEP) Using Mutation Based on Adaptive Mutation Operator (AMO) Applied For Optimal Reactive Power Dispatch", ARPN Journal of Engineering and Applied Sciences, VOL. 11, NO. 14, JULY 2016.

[16] Rebecca Ng Shin Mei, Mohd Herwan Sulaiman, Zuriani Mustaffa, "Ant Lion Optimizer for Optimal Reactive Power Dispatch Solution", Journal of Electrical Systems, "Special Issue AMPE2015", pp. 68-74.2016.

[17] Mahaletchumi Morgan, Nor Rul Hasma Abdullah, Mohd Herwan Sulaiman, Mahfuzah Mustafa, Rosdiyana Samad, "Benchmark Studies on Optimal Reactive Power Dispatch (ORPD) Based Multi-objective Evolutionary Programming (MOEP) Using Mutation Based on Adaptive Mutation 
Adapter (AMO) and Polynomial Mutation Operator (PMO)”, Journal of Electrical Systems, 12-1, 2016.

[18] Rebecca Ng Shin Mei, Mohd Herwan Sulaiman, Zuriani Mustaffa, Hamdan Daniyal, "Optimal Reactive Power Dispatch Solution by Loss Minimization using Moth-Flame Optimization Technique”, Applied Soft Computing, Volume 59, October, Pages 210-222, 2017.

[19] Kaveh A, Talatahari S. A hybrid particle swarm and ant colony optimization for design of truss structure, Asian Journal of Civil Engineering, 9(2008) 329-48.

[20] Camp CV, Bichon BJ. Design of space trusses using ant colony optimization, Journal of Structural Engineering, 130(2004) 741-51.

[21] Camp CV, Bichon BJ, Stovall SP. Design of steel frames using ant colony optimization, Journal of Structural Engineering, 131(2005) 369-79.

[22] Eberhart R, Shi Y. Engineering optimization with particle swarm. In: IEEE swarm intelligence symposium, Indianapolis, 2003, pp. 53-57.

[23] Hassan R, Cohanim B, de Weck O, Venter G. A comparison of particle swarm optimization and the genetic algorithm. In: 1st AIAA Multidisciplinary Design Optimization Specialist Conference. No. AIAA-2005-1897.

[24] Angeline P. Evolutionary optimization versus particle swarm optimization: philosophy and performance difference, Proceeding of the Evolutionary Programming Conference, San Diego, USA, 1998.

[25] Shelokar PS, Siarry P, Jayaraman VK, Kulkarni BD. Particle swarm and ant colony algorithms hybridized for improved continuous optimization, Applied Mathematics and Computation, 188(2007) 129-42.

[26] Vander plaats GN. Numerical optimization techniques for engineering design: with application. 2nd ed. New York: McGraw-Hill, 1984.

[27] Dorigo M. Optimization, learning and natural algorithms (in Italian), PhD Thesis. Dipartimento di Elettronica, Politecnico di Milano, IT, 1992.

[28] Dorigo M, Caro DG, Gambardella LM. Ant algorithms for discrete optimization, Art if Life, 5(1999) 137-72.

[29] Eberhart RC, Kennedy J. A new optimizer using particle swarm theory. In: Proceedings of the sixth international symposium on micro machine and human science, Nagoya, Japan, 1995.

[30] Li LI, Huang ZB, Liu F, Wu QH. A heuristic particle swarm optimizer for optimization of pin connected structures, Computers and Structures, 85(1997) 340-9.

[31] Gholizadeh S. Optimum Design of Structures by an Improved Particle Swarm Algorithm, Asian Journal of Civil Engineering, 11(2010) 777-93.

[32] S. Surender Reddy, "Optimal Reactive Power Scheduling Using Cuckoo Search Algorithm", International Journal of Electrical and Computer Engineering, Vol. 7, No. 5, pp. 2349-2356. 2017

[33] S.S. Reddy, et al., "Faster evolutionary algorithm based optimal power flow using incremental variables", Electrical Power and Energy Systems, vol. 54, pp. 198-210, 2014.

[34] IEEE, "IEEE 118, 300 -test systems", (1993), http://www.ee.washington.edu/trsearch/pstca/.

\footnotetext{
*Corresponding author.

E-mail address: gklenin@ gmail.com
} 